\title{
Gastrointestinal complications and esophageal stenosis after crack cocaine abuse
}

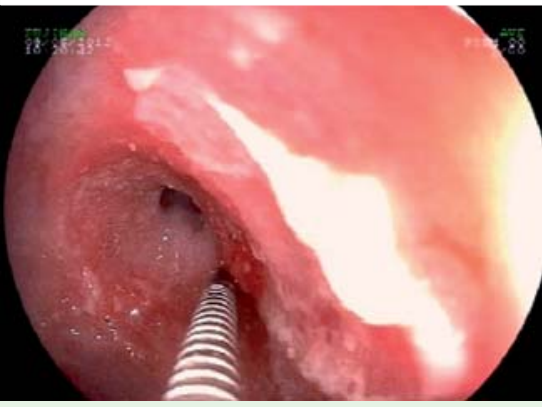

Fig. 1 Upper gastrointestinal endoscopy showing diffuse erythema and mucosal breaks involving more than $75 \%$ of esophageal circumference, food stasis and esophageal stricture $30 \mathrm{~cm}$ from the superior dental arch. The patient was a 29-year-old man with abdominal pain in whom prior exploratory laparotomy had revealed an ischemic segment of the small bowel and a perforated gastric ulcer next to the prepyloric region.

We describe the case of a 29-year-old man who presented to the emergency room complaining of sudden and severe abdominal pain for 3 days. Evaluation on admission revealed low blood pressure, an increased heart rate, and tachypnea. Abdominal examination revealed a positive Blumberg sign and an abdominal radiograph showed pneumoperitoneum requiring urgent surgical evaluation. In the operating room, the emergent exploratory laparotomy revealed an ischemic segment of the small bowel and a perforated gastric ulcer next to the prepyloric region. Following appropriate surgical management and a favorable course over 17 days in hospital, the patient was discharged.

However, 14 days after discharge, the patient returned due to dysphagia for solid foods and vomiting. An upper gastrointestinal endoscopy (UGE) showed diffuse erythema and mucosal breaks involving more than $75 \%$ of the esophageal circumference, food stasis, and an esophageal stricture $30 \mathrm{~cm}$ from the superior dental arch ( Fig.1). An esophageal radiograph showed irregular narrowing of the distal segment of the esophagus over about $13 \mathrm{~cm}$ ( Fig.2). A provisional diagnosis of complicated esophagitis was considered and the patient underwent a 30-day course of a proton pump inhibitor, without improvement. UGE was re-

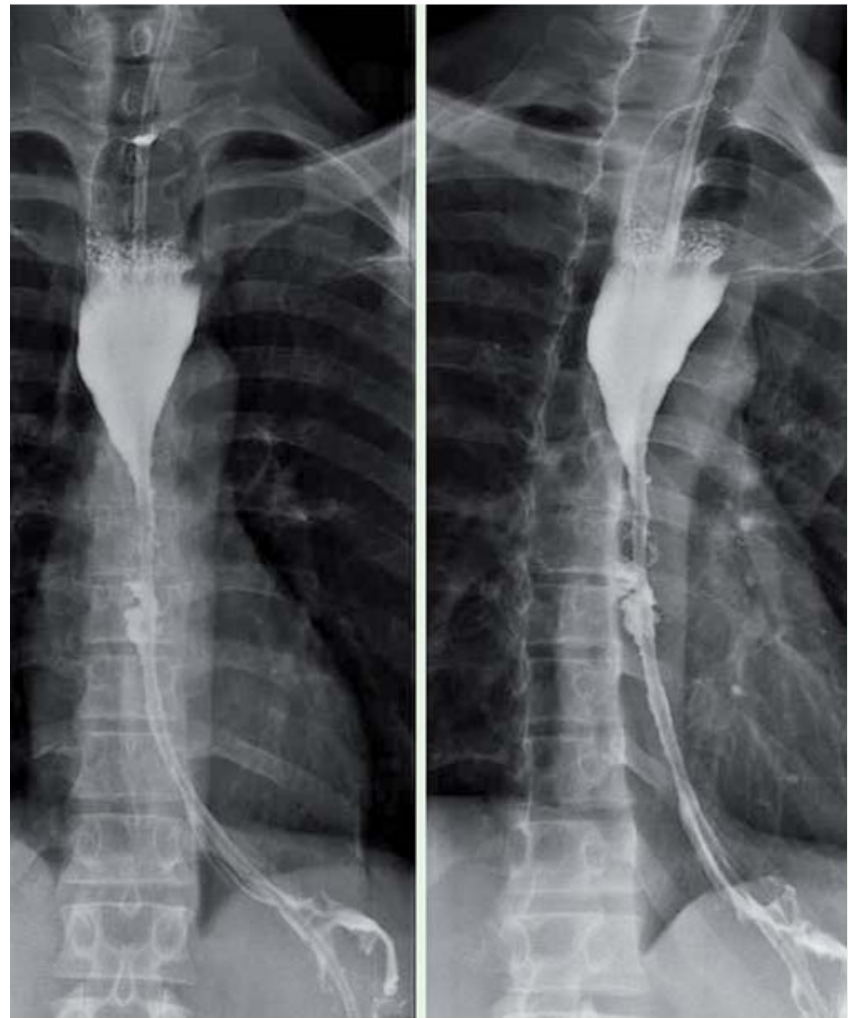

Fig. 2 Upper gastrointestinal tract barium radiograph showing narrowing of and severe injury to the esophagus and stomach.

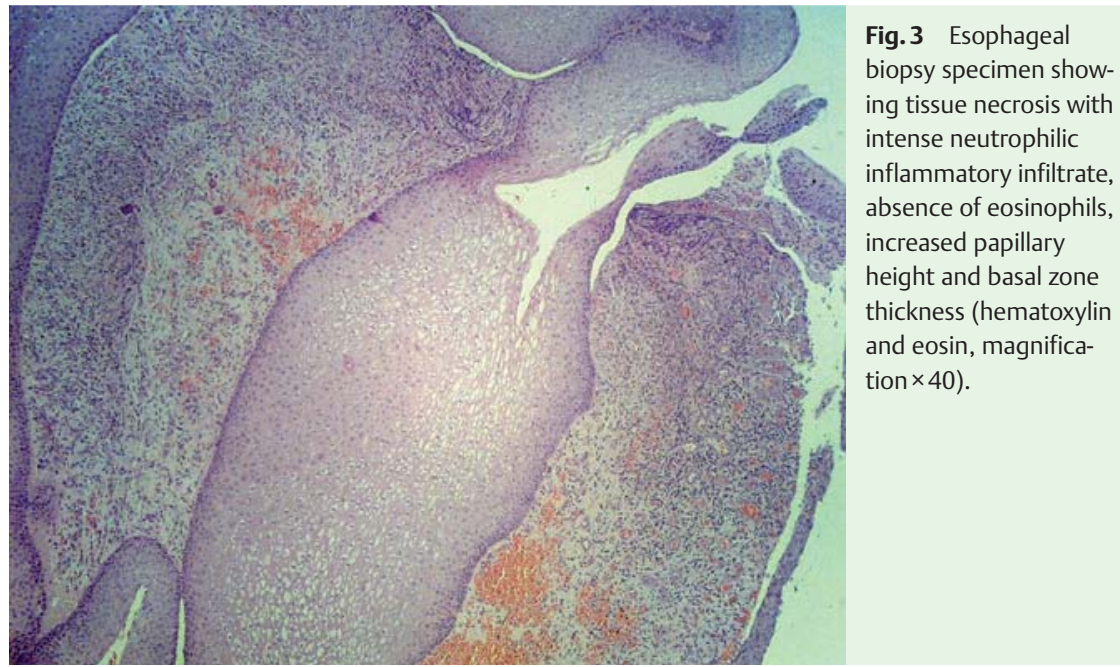

peated for sampling, and histological examination showed areas of tissue necrosis with intense neutrophilic inflammatory infiltrate, absence of eosinophils, increased papillary height and basal zone thickness, suggesting caustic esophageal injury ( Fig.3). The patient then admitted using crack cocaine daily over the past 10 years; he used a cheaper mixture of cocaine, baking soda, gasoline, and glass dust [1]. He also mentioned having a common habit of sucking the plastic wrapper in which the drug was provided, and sometimes swallowing small amounts of crack cocaine. With this last piece of the puzzle in place, a diagnosis of esophageal stricture due to caustic ingestion was established as well as a pre- 
sumed correlation with the previous episode of perforation of gastric ulcer and ischemic colitis [2-7]. The patient was reevaluated by a surgical team for definitive treatment.

Endoscopy_UCTN_Code_CCL_1AB_2AC_3AD and Endoscopy_UCTN_Code_CCL_1AC_2AD

\section{Competing interests: None}

\section{C. Appel-da-Silva ${ }^{1}$, R. B. D'Incao ${ }^{1}$,} V. S. Antonello ${ }^{2}$, E. Cambruzzi ${ }^{3}$

${ }^{1}$ Department of Gastroenterology and Endoscopy, Hospital Mãe de Deus, Porto Alegre, Rio Grande do Sul, Brazil

${ }^{2}$ Department of Infectious Diseases, Hospital Fêmina/ Grupo Hospitalar Conceição, Porto Alegre, Rio Grande do Sul, Brazil

${ }^{3}$ Department of Clinical Pathology, Hospital Nossa Senhora da Conceição, Porto Alegre, Rio Grande do Sul, Brazil

\section{References}

1 Cole C, Jones L, McVeigh J et al. CUT: a guide to adulterants, bulking agents and other contaminants found in illicit drugs. Liverpool John Moores University: Centre for Public Health, Faculty of Health and Applied Social Sciences; 2010

2 Young J, Beech D, Offodile R. Foreign body ingestion and management: "I swallowed a crack pipe". Am Surg 2007; 73: 1144-1146

3 Kodali VP, Gordon SC. Gastrointestinal hemorrhage secondary to crack cocaine. Gastrointest Endosc 1995; 41: 604-605

4 Lingamfelter $D C$, Knight $L D$. Sudden death from massive gastrointestinal hemorrhage associated with crack cocaine use: case report and review of the literature. Am J Forensic Med Pathol 2010; 31: 98 -99

$5 \mathrm{Kram}$ HB, Hardin E, Clark SR et al. Perforated ulcers related to smoking 'crack' cocaine. Am Surg 1992; 58: 293-294

6 Wattoo MA, Osundeko O. Cocaine-induced intestinal ischemia. West J Med 1999; 170 : 47-49

7 Chan YC, Camprodon RAM, Kane PA et al. Abdominal complications from crack cocaine. Ann R Coll Surg Engl 2004; 86: 47-50

\section{Bibliography}

DoI http://dx.doi.org/ 10.1055/s-0033-1344422

Endoscopy 2013; 45: E286-E287

(c) Georg Thieme Verlag KG

Stuttgart · New York

ISSN 0013-726X

Corresponding author

M. C. Appel-da-Silva

Rua Dona Laura

87/202 - Porto Alegre

Rio Grande do Sul

Brazil

Fax: +55 5132226891

marceloappel@yahoo.com.br 